\title{
Banking Concentration and Financial Stability: New Evidence from a Developing Country
}

\author{
Antony Rahim* Peter W Muriu Odhiambo Sule \\ School of Economics, University of Nairobi, Kenya
}

\begin{abstract}
The policy debate on the trade-off and synergies between bank concentration and financial stability remains unresolved. Previous studies suggest two hypotheses; 'concentration-stability' and 'concentration-fragility'. This paper investigated the effect of bank concentration on financial stability in Kenya using Structural Equation Modelling (SEM) for the period 1990-2017. Estimation results reveal that high concentration leads to instability of the financial system. Further, increased competition improves stability of the financial system while regulation positively affects financial stability and bank concentration. Therefore, policies that ensures less bank concentration and enhance bank competition may significantly improve financial stability.
\end{abstract}

Keywords: Financial stability, Banking Fragility, Structural Equation Model

JEL classification: G21, G28.

DOI: $10.7176 / \mathrm{EJBM} / 11-25-08$

Publication date:September $30^{\text {th }} 2019$

\section{Introduction}

Bank concentration is the extent to which the banking sector is controlled by few larger banks in terms of their market share (Beck et al., 2003). Higher bank concentration in a competitive market is associated with greater financial inclusion, which fosters financial development and stability (Owen and Pereira, 2018). The main objective of this study is to investigate the effect of bank concentration on financial stability in Kenya. There were 49 commercial banks operating in Kenya as at the end of December 2000. Out of these banks, the government of Kenya owned five while four banks were locally incorporated foreign owned banks. The remaining 40 banks were privately owned domestically, with three banks having subsidiaries outside Kenya (CBK, 2000). The number of locally owned private commercial banks marginally declined to 28 as at the end of 2012 while foreign owned banks increased to 13 . Out of the 13 foreign owned banks, 9 were local subsidiaries while 4 were branches of foreign banks. Further, the government had majority shares in three privately owned commercial banks (CBK, 2012).

By the end of December 2017, the Kenyan banking sector had 43 commercial banks. The number of domestic privately owned banks decreased from 28 in 2012 to 24 by 2017 while the number of foreign owned banks increased by one to 14 over the same period. Out of the fourteen foreign owned banks, 11 had subsidiaries while three had branches in Kenya. The government had a majority shareholding in three commercial banks, which included National bank of Kenya, Kenya commercial bank and Consolidated bank of Kenya. This trend shows that despite the reduction in the number of locally owned commercial banks, they still dominate the Kenyan banking sector (CBK, 2017).

In 2010 CBK decided to categorize banks in terms of weighted composite market share index (WCMSI) which consisted of deposit accounts, loan accounts, capital size and asset base (CBK, 2010). Based on these criteria, a bank is considered large if it has a WCMSI greater than 5\%; medium banks have WCMSI from $1 \%$ to $5 \%$ while small banks have a WCMSI less than 1\%. Figure 1 shows the trend of changes in market share based on WCMSI among the three peer categories for the period 2010 to 2017. The WCMSI of large sized banks remained steady high between 2010 and 2017. However, it continuously reduced from 56\% in 2010 to a record low of $50 \%$ in 2014 but later increased to $66 \%$ as at the end of 2017 . The reduction was attributed to increased competition which saw the market share of medium banks steadily increasing to $35 \%$ in 2014 up from 7\% in 2006. Further, continuous innovations in the banking sector led to increased deposit base of banks which led to three medium banks graduating to the large peer group as at December 2017, increasing the WCMSI of large banks to $66 \%$.

Despite the banking sector in Kenya being concentrated with few large banks between 2010 and 2017, the medium sized banks gained market share of about $8 \%$ from other peer groups. By the end of 2017, five large banks commanded a market share of $66 \%$ up from $65 \%$ in 2016. This was due to improved deposit mobilization that increased by $16.3 \%$. Further, 11 medium sized banks increased their market share from $26 \%$ in 2016 to $26.10 \%$ in 2017. Combined market share of small peer group reduced from 9\% in 2016 to $8 \%$ in 2017 . 
Figure 1: Weighted Composite Market Share Index by Bank Size

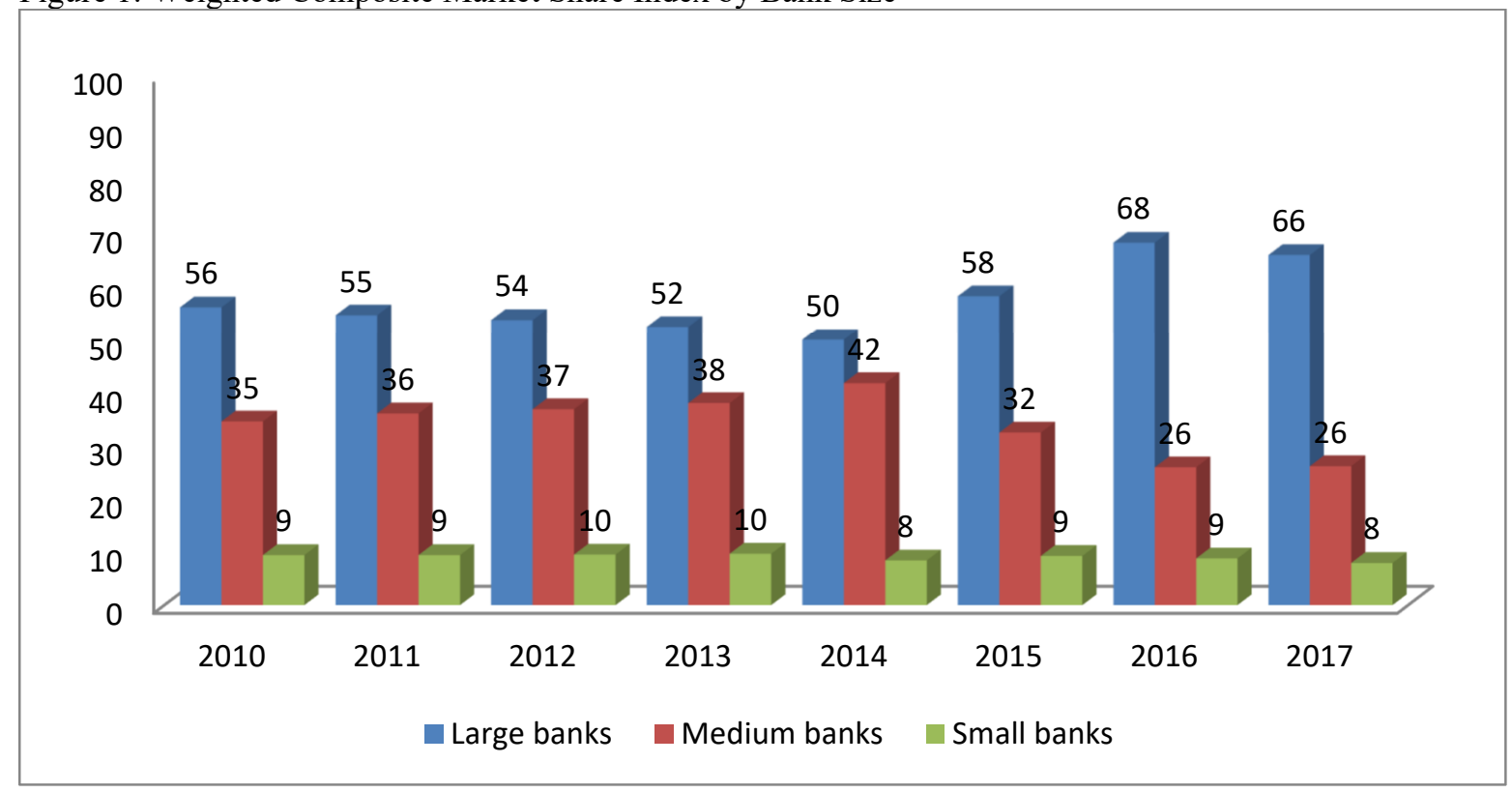

Source: CBK Bank Supervision Report (various issues)

By December 2018, five banks in the large peer group controlled a market share of $68 \%$ up from $66 \%$ in the previous year. These banks included Kenya Commercial Bank, Equity bank, Co-operative bank, Standard Chartered bank and Barclays bank. Table 1 indicates that as the market share of five largest banks in Kenya reduced bank stability improved as reflected by the reduction of the ratio of gross non-performing loans to gross loans.

Table 1: Bank concentration and financial stability 2000-2017

\begin{tabular}{|l|c|c|c|}
\hline Years & $\begin{array}{c}5 \text { bank concentration } \\
\text { ratio }\end{array}$ & Herfindahl -Hirschman Index & Gross non-performing loans \\
\hline 2000 & 77.01 & 0.83 & 12.66 \\
\hline 2001 & 75.59 & 0.82 & 10.89 \\
\hline 2002 & 74.32 & 0.78 & 11.76 \\
\hline 2003 & 70.10 & 0.75 & 11.33 \\
\hline 2004 & 64.58 & 0.71 & 12.58 \\
\hline 2005 & 62.63 & 0.69 & 12.97 \\
\hline 2006 & 65.47 & 0.63 & 13.61 \\
\hline 2007 & 65.77 & 0.58 & 13.88 \\
\hline 2008 & 62.93 & 0.51 & 16.30 \\
\hline 2009 & 62.18 & 0.45 & 14.33 \\
\hline 2010 & 59.27 & 0.46 & 15.54 \\
\hline 2011 & 53.93 & 0.43 & 16.12 \\
\hline 2012 & 54.44 & 0.40 & 15.18 \\
\hline 2013 & 49.20 & 0.39 & 14.12 \\
\hline 2014 & 48.02 & 0.38 & 13.52 \\
\hline 2015 & 48.05 & 0.44 & 13.15 \\
\hline 2016 & 50.25 & 0.48 & 13.67 \\
\hline 2017 & 51.45 & 0.49 & \\
\hline
\end{tabular}

Source: World bank GFDD database

Advocates of "concentration-stability" hypothesis argue that few banks are easy to control and can be able to diversify efficiently hence earn high profits, which act as a buffer during financial crises (Beck et al., 2003). On the contrary, "concentration-fragility" hypothesis suggests that fewer banks are large and complex in nature. This makes them difficult to monitor and hence they exploit customers by charging high interests, which induces customers to invest in risky ventures (Boyd and De Nicolo, 2005). Furthermore, bank concentration encourages moral hazard behaviour based on the notion of 'too big to fail' policies (Mishkin, 1999).

The Kenyan banking sector has experienced dramatic reforms in terms of its structure, regulation and status for the period 2000-2018. Among these reforms include, launching of financial sector regulatory framework and regulations that allowed financial innovation and establishment of credit registries. While large banks still control 
more than $50 \%$ of the market share, the debate on how bank concentration and competition affects stability of the financial system is still not clear. Previous, studies in the Kenyan banking sector have investigated the dynamics of concentration and competition among commercial banks with regards to performance, changes in technology and consolidation, leaving the aspect of financial stability (see Kamau et al., 2004; Gudmundsson et al., 2013; Sahile et al., 2015; Mdoe et al., 2016). This study seeks to fill this research gap. Therefore, two critical questions should be given more attention: What is the effect of bank concentration on financial stability in Kenya? Does the banking system support the 'concentration-stability' or 'the concentration-fragility theory'?

This study contributes to existing literature in several ways. There is no study in Kenya that has attempted to examine how bank concentration and competition affects financial stability to the best of our knowledge. Therefore, the outcome of our study may shed more light on how bank concentration affected financial stability before and after the global financial crisis of 2007-2008. It is important to analyze this issue because the banking sector plays an important role in mobilizing and availing funds to economic agents. These agents may be susceptible to financial instability over time (Shijaku, 2016).

Kenya being a developing economy provides a good case to analyze whether 'concentration-stability' or 'concentration-fragility' hypothesis holds. This is because the country has had significant structural reforms and technological innovations since 1990. We also test both the direct and indirect effect of concentration on financial stability by including competition as our mediating variable. Finally, this paper pioneers the use of structural equation model (SEM) technique in analyzing both the direct and indirect effect of bank concentration on financial stability in Kenya. SEM allows us to tackle the problem of approximating measurement errors.

\section{Previous Evidence}

There are two strands in the literature that seek to explain the relationship between bank concentration, competition and financial stability. These include "concentration-stability" and "concentration-fragility" hypotheses.

The "concentration-stability" hypothesis suggests that there is a positive correlation between bank concentration and stability of the financial system through profitability channel (Freixas and Rochet, 2008; Berger et al., 2009; Vives, 2010; Berger and Bouwman, 2013), diversification channel (Evrensel, 2008), efficiency channel (Fernandez et al., 2010; Cifter, 2015) and easy supervision. Chang et al. (2008) used the structural matrix approach on Brazilian data between 2000 and 2005 to study the effect of bank concentration on non-performing loans. The study also exploited the Hirschman-Herfindahl index to proxy bank concentration. They found out that a concentrated banking system is less vulnerable to financial crisis. Further, Vives (2010) found that few banks in a concentrated market earn greater profits that act as a buffer during financial crises. This finding is consistent with that of Freixas and Rochet (2008). Evrensel (2008) used survival time analysis to show that bank concentration improves the survival time of banks during a crisis using 79 countries between 1980 and 1997 . It is therefore apparent that bank concentration significantly reduces banks' fragility during a crisis.

Diversification also plays an important role in ensuring financial system stability. A concentrated banking system is able to diversify its portfolio to earn more profits. For instance, using a simulation approach to examine the impact of asset portfolio diversification on financial stability in Austria, Frey and Hledik (2018) conclude that diversification at individual bank level improves financial stability. Furthermore, Fernandez et al. (2010) in their study of 84 countries over the period 1980-2004 established that bank size matters when it comes to easy access of information and prevention of adverse selection problems. In addition to these channels, a more concentrated banking system makes it easier for the regulatory authority to monitor and supervise banking activities. This ensures that there is efficient prediction and mitigation of a financial crisis. Contagion risks are also prevented before they occur (Demirguc-Kunt et al., 2010). Therefore, concentration ensures easy regulation of banks. Ali et al. (2015) analyzes the effect of bank concentration on financial stability in developed and developing countries over the period 1980 to 2011. Using a Logit model, the authors conclude that concentration has a stabilizing effect on financial stability in developing countries. Further, Bara et al. (2017) examine how bank concentration affects financial development and stability of South African Development Community (SADC) between 1985 and 2014. Using panel dynamic fixed and random effect models they found that expansion and diversification of banking system may improve financial development which in turn may lead to stability in the financial system.

Proponents of "competition-stability" hypothesis stem from the seminal work by Mishkin (1999). This hypothesis posits that increased competition reduces the possibility that a country will be exposed to a financial crisis. Hu and Xie, (2016) analyze how competition, innovation and risk taking affects profitability of Chinese banks using structural equation model approach. They found that competition is positively correlated to profitability, which leads to financial system stability. Further Kumankoma et al. (2018) analyze how freedom and competition affects profitability of 139 commercial banks in 11 Sub-Saharan Africa (SSA) countries using system GMM for the period 2006-2012. They found that higher market power is significant in determining banks' profitability but efficiency plays a more important role in determining profitability. Profitability would then lead to bank stability in the long run. Further, using data of 978 banks of 55 developing economies over the period 2000 to 2007, Amidu and Wolfe (2013) examine the outcome of diversification on competition and stability. The study 
used three stage least square regression and H-statistics (a non-structural methodology) to estimate competition. They found out that competition also increases diversification in both non-interest revenue and interest revenue of banks. Consistent with this finding is that of Sanya and Wolfe (2011).

On the contrary, "concentration-fragility" hypothesis argues that too much concentration may lead to higher lending rates and risk of default, difficulty in monitoring banks and moral hazard problem due to the notion of "too big to fail" policies (Berger et al., 2009; Soedarmono et al. 2013; Feldman, 2015). Large banks encourage investment in more risky ventures, which have an impact on stability of the financial system. This situation is evident when large banks look for ways to minimize monitoring costs by over lending in one sector of the economy. As a result, there will be reduced diversification of loan portfolios and banks become more vulnerable. Soedarmono et al. (2013) found that despite banks holding high capital in a concentrated market, the amount of assets they own is not large enough to mitigate the effect of non-payment risks associated with higher risk taking business organizations. Berger et al. (2009) reveals that larger banks tend to increase their lending rates, which in turn lead to adverse selection that attracts risky bank customers. Accumulation of risky assets increases fragility of banks. Further, Shijaku (2017) analyzed the effect of concentration on bank stability in Albania over the period 2008 to 2015 using a balanced panel dynamic two-step General Method of Moments (GMM) regression. He found that macroeconomic variables play an important role in determining stability of the financial system, and that bank specific variables also significantly affects bank stability. His results confirmed the "concentration-fragility" hypothesis.

Literature on competition and financial stability seems to be consistent with competition-fragility hypothesis (Agoraki et al., 2011; Beck et al., 2013; Cifter, 2015; Huljak, 2015; Kick and Prieto, 2015; Leroy and Lucotte, 2016). When there is perfect competition in the banking sector each bank mobilizes few customers as reflected by little sum of deposit in their till. Therefore, no bank has an effect in determining interest to be charged in the market. However, firms will be induced to expand their business and take more risks as long as they earn positive returns. This increased competition may lead to investments in risky ventures that would trigger systemic risks (Agoraki et al., 2011). Berger et al. (2008) analyzes the effect of competition on financial stability by employing GMM regression with robust standard errors of 8,235 banks in 23 developing countries. They established that competition reduces the ability of banks to control prices of their products and at the same time acts as an incentive for banks to invest in more risky ventures, which are a threat to financial stability.

In the same vein, Agoraki et al. (2011) employ static panel data instrumental variable regression on Eastern and Central European banks over the period 1998 to 2005. They found that lower bank concentration encourages competition, which in turn increases credit risk and higher likelihood of default. Further, Leroy and Lucotte (2016) examine the trade-off between competition and financial system stability of 54 European banks using Stochastic Frontier Analysis (SFA) between 2004 and 2013. Using Lerner index to proxy competition and bank Z-score for financial stability the study confirms competition-fragility hypothesis. This finding is consistent with that of Cifter (2015). Consequently, Kick and Prieto (2015) established that competition that reduces regulation does not automatically improve financial stability or their pliability to shocks emanating from monetary policies. Using a sample data of 415 banks in Central and Eastern European Countries (CEEC) between 1997 and 2012 and a fixed effect panel regression, Huljak (2015) established that bank competition increased instability of the financial sector over time. This finding supports Berger et al. (2009) and Jimenez and Saurina (2013).

Reviewed empirical literature suggests different directions on the interlinkages between concentration, competition and financial stability. The difference is either unidirectional or bidirectional from country to country depending on the methodology used. The evidence is however mixed between 'concentration-stability' and 'concentration-fragility' hypothesis. Existing literature further fails to evaluate how bank concentration and competition affects financial stability in a multivariate level. This provides a more realistic picture of how our variables of interest interract with high significance levels. Finally, empirical literature on how bank concentration and competition affects financial stability in certain regional contexts such as the Sub-Saharan African (SSA) region and more specifically in Kenya remains unexplored. This study seeks to fill this knowledge gap.

\section{Methodology and data}

\subsection{Theoretical Framework}

We follow the efficient structure hypothesis advanced by Demsetz (1973) and later extended by Catena (2000). This hypothesis looks at a partial equilibrium model in a perfectly competitive market with heterogeneous banking industry. The model assumes there are many banks in the market that are able to perform their intermediary role efficiently. Despite any bank being able to provide services $b \in[0,1]$ in the market, there is only one subset $N \subseteq$ $[0,1]$ in all equilibrium, which competes specified as follows;

$N=\{b \in[0,1] q(b)>0\}$

Where $q(b)$ represents the production function of bank $b$.

A customer maximizes his consumption of bank products and services given his budget constraint; 
$\max _{d(b)} \int_{0}^{1} d(b) d b$

Subject to;

$Y=\int_{0}^{1} p(b) d(b) d b$

Where bank products and services provided by bank $b$ is supplied at price $p(b)$ and the quantity demanded is $d(b)$. A customer spends his total income $Y$ to purchase bank's products and services. Since banks operate in a perfectly competitive market they all sell their products and services at the same price as follows.

$d(b)>0 \Rightarrow p(b)=p$ for all $b$

All banks in the market have different total cost function and therefore they are heterogonous. Bank $b$ supplies quantity $q(b)$ of its products and services at a total cost $T C[b, q(b)]$. We present the total cost of bank $b$ as follows. $T C[b, q(b)]=\omega(b)+V C[\theta(b), q(b)]$

Where $\omega(\cdot)$ represents total fixed costs, while $V C[\cdot]$ denotes bank's variable costs. X-inefficiency of bank $b$ is measured by $\theta(b)$. We differentiate efficiency and cost of entry concerns by assuming that $\omega(\cdot)$ depends on bank $b$ but not on $\theta(b)$. Variable costs are presented in $[\theta(b), q]=\theta(b) \cdot k(q)$. Where $k(q)$ is the same in all banks while $k(q) / q$ represents the average variable costs curve, which is a $U$ shaped curve. It is further assumed that $\omega(b)$ and $\theta(b)$ are step functions. We model our supply structure by a vector-valued function as follows;

$V(b)=\left[\begin{array}{l}\omega^{V}(b) \\ \theta^{V}(b)\end{array}\right]$

Bank $b$ assumes that the prices of its rival products are constant and maximizes its profit as follows;

$\pi(b)=\max \left\{\max _{q(b)} p q(b)-T C(b, q(b), 0\}\right.$

In a perfect competitive market, each bank is assumed to be a price taker. However, each bank can decide not to produce. This is represented by the outer max (·) function. Equation (4) states that each bank charges the same price. Therefore for all banks $h(b)>0$. Therefore, price becomes;

$p=M C[b, q(b)]=\theta(b) k^{\prime}(q(b))$

Where $M C$ is the marginal cost of a given bank $b$. At equilibrium, we expect the supply of bank products and services to be equal to demand by the consumers.

$d(b)=q(b)$ for all $b \in N$

We then integrate equation (9) for all $b$ to arrive at;

$D(p)=\int_{0}^{N} d(b) d b=Q(p)=\int_{0}^{N} q(b) d b$

Equation (10) implies that the aggregate demand $D(p)$ is equal to aggregate supply $Q(p)$ of bank products and services. Further, combining the budget constraint in equation (3) and the aggregate demand curve in equation (10) with all banks changing the same price, we obtain a negative sloping demand curve in the form: $D(p)=1 / p$. If we describe the minimum average cost of bank $b$ as follows;

$A C^{*}(b)=\min _{q} \frac{k(q) \theta(b)+\omega(b)}{q}$

At equilibrium price $p$ the minimum average cost is given by $\min _{b} A C^{*}(b)<p$. If the equilibrium condition holds, then when price $(p)$ is equal to the minimum average cost $\left[\min _{b} A C^{*}(b)\right]$ bank $b$ will be undecided on whether to produce or not. Bank $b$ will only produce when price $(p)$ is higher than the minimum average cost $\left[\min _{b} A C^{*}(b)\right]$. This implies that the production function and profitability for any bank $(b)$ in the market is strictly increasing in price $(p)$. Therefore, at an equilibrium price $(p)$ the set of competing banks is represented by $N(p)=$ $[0, \max \vartheta(p)]$. Where $\vartheta(p)$ is a non-decreasing function apart from some finite amount of prices.

\subsection{Empirical Model}

There is no consensus on how concentration affects financial stability. The appropriate model to explore this relationship is a structural equation model ( $\mathrm{Hu}$ and Xie, 2016; Li, 2016). A detailed explanation of SEM can be found in Kline (2011). In our SEM model, concentration is assumed to have a single direct effect and one indirect effect on financial stability. The indirect outcome is intervened by competition and the indirect path is concentration-competition-stability respectively. SEM encompasses two models that include the measurement and structural model. The measurement model is specified as:

$Z=\Phi_{z} \Omega+\Lambda$,

Where $\mathrm{Z}$ is a vector of exogenous variables that can be observed $z ; \Omega$ represents a vector of exogenous latent indicator $\rho$. The matrix of factor loading $\Phi_{z}$ is represented by $\varphi_{z}$. When we link $z$ to $\rho$ then we have $\Lambda$ as a vector of measurement errors $\varepsilon$. Therefore, our exogenous variable is defined as; 
$\left[\begin{array}{c}z_{1} \\ z_{2} \\ \vdots \\ z_{n}\end{array}\right]=\left[\begin{array}{c}\varphi_{z 1} \\ \varphi_{z 2} \\ \vdots \\ \varphi_{z_{n}}\end{array}\right] \rho+\left[\begin{array}{c}\varepsilon_{1} \\ \varepsilon_{2} \\ \vdots \\ \varepsilon_{n}\end{array}\right]$

In our study, bank concentration is defined as $\rho$ and measured by observable variables $z_{1}, z_{2}, \ldots \ldots z_{n}$. The coefficients of bank concentration $(\rho)$ are represented by $\varphi_{z 1}, \varphi_{z 2}, \ldots, \varphi_{z n}$ while $\varepsilon_{1}, \varepsilon_{2}, \ldots ., \varepsilon_{n}$ denotes the error term. Likewise, we present the measurement model of the endogenous indicators as;

$\left[\begin{array}{c}y_{1} \\ y_{2} \\ y_{3} \\ : \\ y_{n}\end{array}\right]=\left[\begin{array}{ccc}1 & 0 & 0 \\ \lambda_{1 \gamma} & 0 & 0 \\ \lambda_{2} & \lambda_{3} & 0 \\ : & : & : \\ 0 & 0 & \lambda_{n}\end{array}\right]\left[\begin{array}{l}\gamma_{1} \\ \gamma_{2}\end{array}\right]+\left[\begin{array}{c}\vartheta_{1} \\ \vartheta_{2} \\ \cdot \\ \cdot \\ \vartheta_{n}\end{array}\right]$,

Where $y_{1}, y_{2}, y_{3} \ldots \ldots, y_{n}$ are variables that proxy the endogenous variables, which include competition $\gamma_{1}$ and financial stability $\gamma_{2}$. However, it should be noted that not all measurement variables have been included to proxy our endogenous variables. For instance, we know that macroeconomic environment, bank regulations and the level of financial inclusivity also affects bank competition and financial stability but are not used as measurement variables. An endogenous variable mutually represents a cause or effect of an outcome. In our case competition can be regarded as both the cause of financial stability and has an effect of bank concentration. Further, $\vartheta_{1}, \vartheta_{2}, \ldots \ldots, \vartheta_{n}$ represents the residual terms of the estimated model.

Our structural equation model therefore merges the measurement and the path model by taking residuals of measurement observable variables into consideration as follows;

$\mathrm{N}=\mathrm{AN}+\Omega \Psi+\mathrm{Y}$,

Where $\mathrm{N}$ represents a matrix of path coefficients $\eta$, which explains the link between endogenous latent construct. Further, $\Omega$ is the path matrix of coefficient $\tau$ that explains the direct effects of exogenous measurement variable on endogenous measurement indicators. Finally, $\mathrm{Y}$ is a vector of estimation residuals $v$. The SEM model is presented as follows:

$\left[\begin{array}{l}\gamma_{1} \\ \gamma_{2} \\ \gamma_{3}\end{array}\right]=\left[\begin{array}{ccc}0 & 0 & 0 \\ \eta_{21} & 0 & 0 \\ 0 & \eta_{32} & \eta_{33}\end{array}\right]\left[\begin{array}{l}\gamma_{1} \\ \gamma_{2} \\ \gamma_{3}\end{array}\right]+\left[\begin{array}{l}\eta_{1} \\ \eta_{2} \\ \eta_{3}\end{array}\right] \rho+\left[\begin{array}{l}v_{1} \\ v_{2} \\ v_{3}\end{array}\right]$

\subsection{Definition and Measurement of Variables}

Existing empirical literature have used different concentration ratios to measure market share of firms in the financial sector. These ratios include: Herfindahl-Hirschman Index (HH), Hannah and Kay Index (HKI), Bank Concentration Ratio $\left(C R_{n}\right)$, Rosenbluth Index (RI), U-Index (U), Hause Index (HI), Entropy estimations, Hall and Tideman Index (HTI) and Comprehensive Industrial Concentration Index (CICI) (Bikker and Haaf, 2002). However, $\mathrm{HH}$ is the most commonly used measure of concentration in existing literature and always acts as a yardstick for the assessment of other concentration measures (Bikker and Haaf, 2002). HH highlights the significance of larger banks by assigning them bigger weights than smaller banks. Consequently, it includes each individual bank, such that random disconnections and insensitivity in market share allocation is mitigated (Ciapanna and Rondinelli, 2011). HH is measured as the sum of squares of the market share of loans, assets, or deposits of each individual bank in the banking sector.

The ratio is defined as;

$$
H H I=\sum_{i=1}^{n}\left(\frac{x_{i}}{X}\right)^{2} \quad 1 \geq H H I \geq \frac{1}{n},
$$

Where $X$ is the joint assets of all commercial banks in a country, $x_{i}$ is the total asset of bank $i$ in a given period and there are $n$ banks in the country. The HHI varies between 1 and $1 / n$. A value of 1 signifies monopoly market and the lowest value of $1 / n$ implies all banks are equal in size. According to Galetic and Obravodic (2018), bank concentration is high if the value is more than 0.18 , medium if it ranges between 0.1 and 0.18 . It is small when it is below 0.1. Therefore, Davies (1979) posits that the HHI becomes less responsive to alterations in the number of banks when the number of banks increases. We compute the HHI of the banks in Kenya and use it as one of the measures of bank concentration.

Another commonly used measure of bank's market share is the banks' concentration ratio $\left(C R_{n}\right)$ which measures the sum of assets held by $n$ largest banks divided by the total assets held by the banks sector computed as follows;

$C R_{n}=\sum_{i=1}^{n} \frac{x_{i}}{X}$

Policy makers often utilize this ratio when measuring the market composition and formulating bank regulations (Berger et al., 2004; Beck et al., 2004, Ali et al., 2012). Regulators may utilize concentration ratios by focusing on how size; number of banks and distribution affects competition. Our study employs the share of assets 
held by the five largest banks in Kenya.

Studies conducted on competition and stability make a distinction between two methods; the structural measures emanating from the SCP hypothesis (Mason, 1939; Bain, 1959) and the non-structural estimates originating from the New Empirical Industrial Organization Framework (NEIO) (Lerner, 1934; Panzar and Rosse, 1987; Boone, 2008). The most commonly used structural measure is the market share while non-structural competitive measures are the Lerner Index developed by Lerner (1934); H-statistics introduced by Panzar and Rosse (1987) and the modified Boone Indicator by Boone (2008). Non-structural measures of competition are preferred to structural measures because they provide a more practical setting to measure bank competition and that they have a micro-economic foundation (Bikker and Haaf, 2002; Claessens and Laeven, 2004). Based on existing literature (see Park, 2013; Amidu and Wolfe, 2013) and reliability of the measures, our study adopts the non-structural measures, specifically the Lerner Index, H-Statistics and the Boone Indicator to proxy competition.

Lerner index (LI) is defined as the variation between price and marginal cost as a fraction of price. It is the converse proxy for competition and can be estimated as;

$L I_{i t}=\frac{p_{i t}-m c_{i t}}{p_{i t}}$

Where $p_{i t}$ proxies price of bank $i$ 's output at time $t$ and $m c_{i t}$ is the marginal cost of bank $i$ at time $t$. The LI measured for each bank represents its pricing influence in the market. Where services provided by a given bank are equal to its total asset, $p_{i t}$ is estimated by dividing the total income with total assets (Berger et al., 2009; Beck et al., 2013). LI ranges from 0 to 1 . The value of 1 represents pure monopoly while zero corresponds to a perfect competitive market. LI is preferred to other measures because it can be calculated at firm level over a longer period of time (Leroy and Lucotte, 2006).

H-statistics (HS) introduced by Panzar and Rosse in 1987 (Elzinga and Mills, 2011). Is the summation of elasticities of the reduced form incomes with respect to factor prices. The H-statistics is also referred to as the Panzar and rose Statistics. This measure varies between $-\infty<H \leq 1$. When the H-statistics value is less than zero, the market is a pure monopoly $(-\infty<H \leq 0)$. On the other hand, when the H-statistics lies between zero and one then we have a monopolistic or an oligopolistic market rivalry $(0<H<1)$. When the H-statistics value is equivalent to one $(H=1)$, then we have a perfectly competitive market. The interlinkages between the Lerner Index, the hypothetical elasticities and the H-statistics were well explained by Shaffer (1983). H-statistics is computed as follows;

$H=\sum_{k-1}^{m}\left(\begin{array}{c}\partial R_{i}^{*} / \partial w_{k_{i}} \\ )\end{array}\left(w_{k_{i}} / R_{i}^{*}\right)\right.$

Where * represent variables that are in equilibrium. Market dominance is estimated by the degree to which an alteration in factor input cost $\left(\partial w_{k_{i}}\right)$ is replicated in the equilibrium income $\left(\partial R_{i}^{*}\right)$ received by bank $i$.

Boone indicator (BO) estimates the differences in efficiency of firms in a given sector. Banks compete in the market to achieve high performance. Therefore, for a bank to perform better than its rivals in the market it has to increase its efficiency. This implies that banks that are more efficient significantly improve their performance compared to less efficient banks. Boone indicator links performance with different levels of efficiency (Boone, 2008). The revenue elasticity index known as the Boone index is estimated as follows;

$\pi_{i t}=\delta+\theta \ln \left(M C_{i t}\right)$,

Where $i$ represents an individual bank, while $t$ stands for a sample year. $\pi_{i t}$ symbolizes performance in terms of profit and $M C_{i t}$ is the marginal cost of an individual bank at a given year. Efficient firms with less marginal cost have a higher market command, reduced prices, higher revenues and higher price-cost margins (Aghion et al., 2005). It should be noted that some studies replace market performance with market share when measuring efficiency of banks (Tabak et al., 2011).

Profit in the banking sector is estimated by deducting bank-operating expenses from bank operating income. Further, due to difficulties in measuring the marginal cost we use the average cost by dividing bank operating expense by the revenue. $\theta$ is a proxy for the Boone indicator and it is always negative because it is a decreasing function of revenue as a result of bank's inefficiencies. Higher values of $\theta$ in absolute terms signify tougher competition.

Further, we include bank regulation indicator as a control variable in our estimation. We use capital adequacy (CA) and asset quality (AQ) to proxy micro prudential regulation while minimum capital requirement (MC) and debt to income ratio (DI) is used to represent macro prudential ratio. To ensure stability in the financial system regulatory authorities have to complement macro and micro prudential regulation. This ensures that both idiosyncratic and systemic risks are mitigated in the system (Borio, 2003). Different empirical studies have emphasized on the importance of prudential regulations in ensuring financial system stability (Gudmundsson et al., 2013; Cerutti et al., 2015). Bank regulations also affect the level of bank concentration and competition in the market (Demirguc-Kunt, 2002).

Financial stability, which is one of the endogenous latent construct in our model, is estimated along two proportions that comprise of financial resilience and financial volatility. Banks' Z-score (ZS) and ratio of credit 
provisioning to bank deposit (CB) measure financial resilience (Beck et al., 2013; Cuestas et al., 2017). Volatility of the financial system is represented by standard deviation of bank deposit rate growth (SL), standard deviation of bank lending rate growth (SB) and loan loss reserve to total loan loss (LL) ratio (see Titko et al., 2015; Cihak et al., 2016).

\subsection{Estimation and Testing}

We determined the goodness of fit by employing the Chi square statistics, Comparative Fit Index (CFI), Tucker Lewis Index (TLI), Root Means Square Error of Approximation (RMSEA) and Standardized Root Mean Square Residual (RMSR). We exploited these three measures to evaluate the different model specifications because they provide alternatives for choosing the most preferred model. A model that has a value close to zero indicates a best fit (Blunch, 2008). We used the Maximum likelihood estimation (MLE) approach to ascertain the link between the latent variables and the indicator variables. We further tested for multicollinearlity among these variables to ensure that there is no correlation among our variables of interest.

\subsection{Data Sources}

Yearly data of our variables of interest for the period 1990-2017 was obtained from World Bank's Global Financial Development Database (GFDD), Thomson Reuter's database and the Central Bank of Kenya (CBK). Our selection of data period was guided by some important changes in bank concentration, competition and financial stability in Kenya. For example since 2004 medium sized banks improved their efficiency hence enhancing competition with large sized banks over time.

\section{Empirical Findings}

We tested the normality of our data using the Jarque-Bera (JB), skewness and kurtosis. The JB test combines both skewness and kurtosis following their coefficients with two degrees of freedom. The null hypothesis in this test follows a normal distribution while the alternative hypothesis suggests otherwise. A normally distributed data is expected to have zero skewness with a kurtosis being equal to three. Any deviation from these values increases the JB statistics. Further, we calculated the standard deviation, mean, maximum and minimum of the data. Table 2 presents the summary statistics.

Table 2: Descriptive Statistics

\begin{tabular}{|c|c|c|c|c|c|c|c|c|}
\hline Variables & Obs & Mean & Std. Dev. & Min & Max & Skewness & kurtosis & $\operatorname{Pr}(\mathrm{JB}$-stat $)$ \\
\hline Herfindahl-Hirschman Index (HH) & 28 & 0.10 & 0.05 & 0.03 & 0.19 & -0.08 & 2.38 & $2.89[0.24]$ \\
\hline 5 Bank Concentration (CR) & 28 & 0.70 & 0.30 & 0.49 & 0.70 & -0.40 & 2.40 & $4.12[0.13]$ \\
\hline $\begin{array}{l}\text { Boone Indicator } \\
\text { (BO) }\end{array}$ & 28 & 0.09 & 0.06 & 0.01 & 0.26 & 0.22 & 2.38 & $0.19[0.91]$ \\
\hline $\begin{array}{l}\text { Panzar-Rosse H-Statistics } \\
\text { (HS) }\end{array}$ & 28 & 0.52 & 0.11 & 0.34 & 0.72 & -0.95 & 3.77 & $1.09[0.65]$ \\
\hline $\begin{array}{l}\text { Lerner Index } \\
\text { (LI) }\end{array}$ & 28 & 0.41 & 0.07 & 0.28 & 0.54 & -0.55 & 2.37 & $0.72[0.70]$ \\
\hline $\begin{array}{l}\text { Capital adequacy } \\
\text { (CA) }\end{array}$ & 28 & 0.38 & 0.26 & 0.11 & 0.88 & -0.65 & 2.89 & $0.30[0.18]$ \\
\hline $\begin{array}{l}\text { Asset quality } \\
\text { (AQ) }\end{array}$ & 28 & 0.44 & 0.21 & 0.15 & 0.80 & -0.32 & 2.15 & $4.95[0.08]$ \\
\hline Minimum capital requirement (MC) & 28 & 0.47 & 0.21 & 0.10 & 0.89 & -0.43 & 2.50 & $4.79[0.09]$ \\
\hline $\begin{array}{l}\text { Debt to operating income ratio of } \\
\text { banks (DI) }\end{array}$ & 28 & 0.49 & 0.25 & 0.11 & 0.87 & -0.75 & 3.10 & $0.80[0.60]$ \\
\hline $\begin{array}{l}\text { Z-score } \\
(\mathrm{ZS})\end{array}$ & 28 & 12.26 & 2.35 & 8.50 & 16.3 & -0.06 & 2.10 & $0.30[0.18]$ \\
\hline $\begin{array}{l}\text { Ratio of Credit Provision to Bank } \\
\text { Deposit }(\mathrm{CB})\end{array}$ & 28 & 0.33 & 0.19 & 0.02 & 0.63 & -0.42 & 1.68 & $3.38[0.12]$ \\
\hline $\begin{array}{l}\text { Standard Dev of Banks' Lending } \\
\text { Rate(SL) }\end{array}$ & 28 & 0.47 & 0.20 & 0.11 & 0.93 & 0.75 & 2.28 & $2.39[0.30]$ \\
\hline $\begin{array}{l}\text { Standard Dev of Banks Deposit Rate } \\
\text { (SB) }\end{array}$ & 28 & 0.31 & 0.16 & 0.09 & 0.67 & 1.46 & 1.63 & $2.88[0.23]$ \\
\hline $\begin{array}{l}\text { Loan loss reserve to total loans ratio } \\
\text { (LL) }\end{array}$ & 28 & 0.51 & 0.17 & 0.10 & 0.80 & -0.99 & 3.22 & $0.93[0.63]$ \\
\hline
\end{tabular}


The maximum mean value of our data is that of the $\mathrm{Z}$-score at 12.26 and the minimum expected value is that of Boone indicator at 0.09 . Most variables are lowly dispersed from their means as reflected by low standard deviations. The highest and lowest values in our data are depicted by the maximum and lowest values. All variables have a significantly peaked distribution as represented by positive kurtosis values. The highest peaked distributions are shown by Panzar Rosse H-statistics and loan loss reserve to total loan loss ratio. All variables were normally distributed at five percent significant level. The adjusted chi-square probability numbers outside the brackets factor in small sample distribution values that delay to converge under the JB statistics. Therefore, our data is normally distributed.

We performed a correlation analysis to ascertain whether there is a strong linear association between our variables of interest. Table 3 shows an inverse relationship between high level of bank concentration and financial stability in Kenya as depicted by variables that represents concentration (HH, CR) and variables that represent financial stability (ZS, CB, SB, SL, LL). This supports the 'concentration-fragility' hypothesis.

Table 3: Correlation Matrix

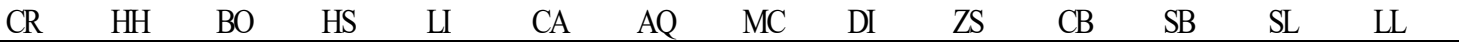

\begin{tabular}{|c|c|c|c|c|c|c|c|c|c|c|c|c|c|c|}
\hline $\mathrm{CR}$ & 1.00 & & & & & & & & & & & & & \\
\hline $\mathrm{HH}$ & 0.30 & 1.00 & & & & & & & & & & & & \\
\hline $\mathrm{BO}$ & -0.42 & -0.21 & 1.00 & & & & & & & & & & & \\
\hline HS & 0.33 & 0.03 & -0.13 & 1.00 & & & & & & & & & & \\
\hline U & 0.40 & 0.41 & -0.15 & -0.31 & 1.00 & & & & & & & & & \\
\hline $\mathrm{CA}$ & -0.35 & -0.32 & 0.27 & 029 & 0.37 & 1.00 & & & & & & & & \\
\hline $\mathrm{AQ}$ & -0.48 & -0.47 & 0.12 & 0.40 & 0.45 & 0.38 & 1.00 & & & & & & & \\
\hline $\mathrm{MC}$ & -0.12 & -0.32 & 0.28 & -0.31 & -0.23 & 0.34 & 0.04 & 1.00 & & & & & & \\
\hline DI & -0.25 & -0.30 & 0.38 & -0.26 & -0.34 & 0.23 & 0.10 & 0.35 & 1.00 & & & & & \\
\hline ZS & -0.71 & -0.47 & 0.33 & -0.08 & -0.02 & 0.29 & 0.28 & 0.32 & 0.08 & 1.00 & & & & \\
\hline $\mathrm{CB}$ & -0.56 & -0.48 & 0.10 & -0.18 & -0.40 & 0.39 & 0.16 & 0.27 & 0.19 & 0.60 & 1.00 & & & \\
\hline SB & -0.11 & -0.41 & 0.05 & -0.18 & -0.02 & 0.24 & 0.13 & 0.26 & 0.26 & 0.29 & 0.33 & 1.00 & & \\
\hline SL & -0.44 & -0.37 & 0.42 & -0.10 & -0.25 & 0.35 & 0.24 & 0.45 & 0.12 & 0.33 & 0.45 & 0.66 & 1.00 & \\
\hline LL & -0.02 & -0.03 & 0.21 & -0.40 & -0.33 & 0.42 & 0.19 & 0.23 & 0.16 & -0.13 & 0.08 & -0.51 & -0.09 & 1.00 \\
\hline
\end{tabular}

\subsection{Exploratory factor Analysis}

We conducted an exploratory factor analysis (EFA) to select the best variables that would sufficiently represent our latent variables to draw meaningful results from our estimation (Thompson, 2004). The results are presented in Table 4. We focused on factors that have Eigen values greater than one to explain our model (Henson and Roberts, 2006). Our EFA identified four factors with Eigen values greater than one explaining $92 \%$ of the deviation in our sample. The first two factors explained $67 \%$ of the variation while the remaining third and fourth factors explained $15 \%$ and $10 \%$ of the variation respectively.

Table 4: Factor Loadings

\begin{tabular}{|l|l|l|l|}
\hline Factor & Eigen value & Proportion & Cumulative \\
\hline 1 & 2.17 & 0.45 & 0.37 \\
\hline 2 & 1.87 & 0.22 & 0.67 \\
\hline 3 & 1.43 & 0.15 & 0.82 \\
\hline 4 & 1.01 & 0.10 & 0.92 \\
\hline 5 & 0.44 & 0.05 & 0.96 \\
\hline 6 & 0.30 & 0.03 & 1.00 \\
\hline 7 & 0.10 & 0.01 & 1.01 \\
\hline 8 & 0.08 & 0.00 & 1.01 \\
\hline 9 & -0.07 & -0.00 & 1.00 \\
\hline 10 & -0.06 & -0.01 & 1.00 \\
\hline 11 & -0.05 & -0.02 & 1.00 \\
\hline 12 & -0.02 & -0.01 & 1.00 \\
\hline 13 & -0.01 & -0.03 & 1.00 \\
\hline 14 & -0.06 & -0.00 & 1.00 \\
\hline
\end{tabular}

We further construct a scree plot to determine the most effective factors that would significantly affect our estimation model. Figure 2 shows the scree plot of the Eigen values. 
Figure 2: Scree Plot of Eigen Values

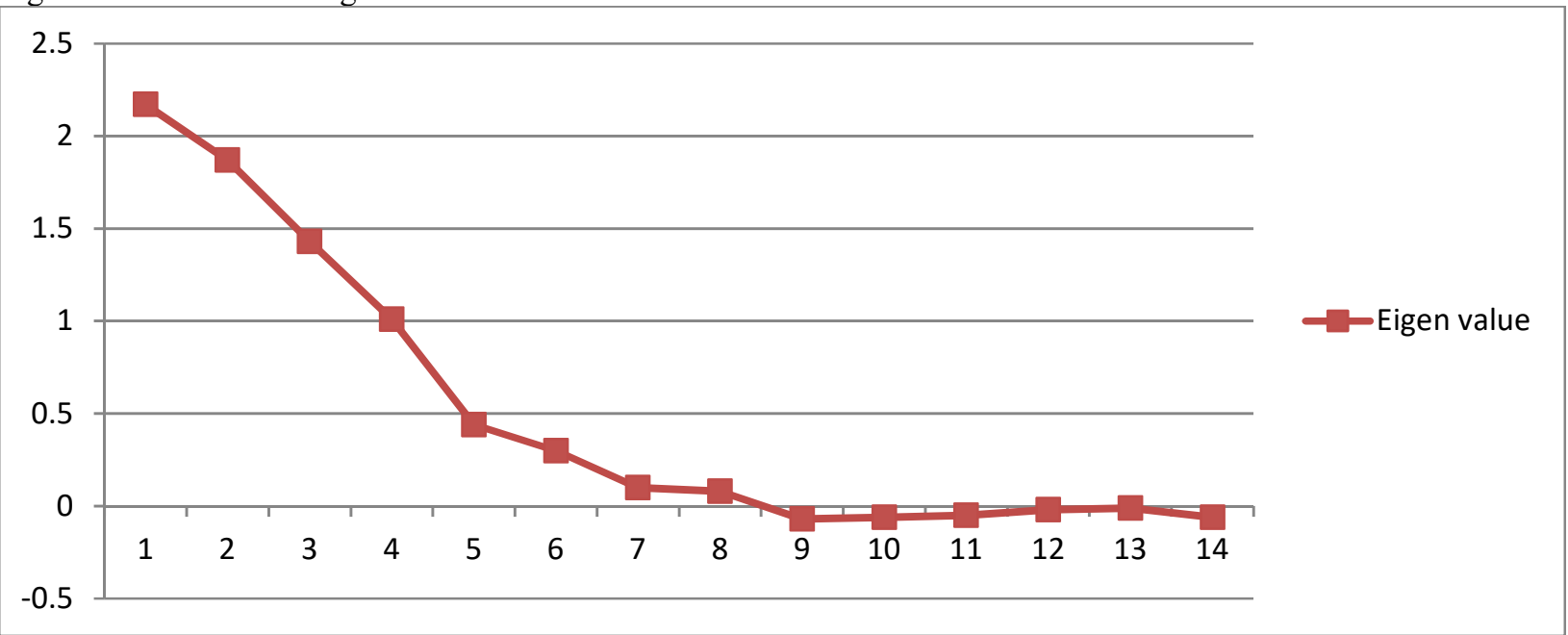

To ensure that we get reliable result to explain our four latent variables we performed a rotation on the four factors to establish the correlation between the factors and the original measurement variables. We further used an orthogonal matrix rotation known as varimax rotation to ascertain the composition of the scale factor. Two variables that had factor loadings of less than 0.5 were dropped. They included minimum capital requirement (MC) and Loan loss reserve to total loans ratio (LL). Table 5 shows how the remaining variables loaded on the three factors.

Table 5: Factor Rotation Matrix Using Varimax

\begin{tabular}{|c|c|c|c|c|c|}
\hline Variable & Factor 1 & Factor 2 & Factor 3 & Factor 4 & Uniqueness \\
\hline $\mathrm{CR}$ & -0.84 & & & & 0.18 \\
\hline $\mathrm{HH}$ & -0.77 & & & & 0.17 \\
\hline $\mathrm{BO}$ & & & 0.91 & & 0.15 \\
\hline $\mathrm{HS}$ & & & -0.60 & & 0.12 \\
\hline LI & & & 0.88 & & 0.18 \\
\hline $\mathrm{CA}$ & & & & 0.78 & 0.07 \\
\hline $\mathrm{AQ}$ & & & & 0.82 & 0.13 \\
\hline DI & & & & 0.72 & 0.05 \\
\hline $\mathrm{ZS}$ & & 0.88 & & & 0.19 \\
\hline $\mathrm{CB}$ & & 0.92 & & & 0.09 \\
\hline SB & & 0.89 & & & 0.19 \\
\hline $\mathrm{SL}$ & & 0.81 & & & 0.10 \\
\hline
\end{tabular}

Factor 1 encompasses variables that represent bank concentration namely: 5 banks concentration ratio (CR) and Herfindahl-Hirschman Index $(\mathrm{HH})$. Factor 2 consisted of variables that proxy financial stability which includes: bank Z-score (ZS), Ratio of Credit Provision to Bank Deposit (CB), standard deviation of bank's deposit rate (SB) and standard deviation of bank's lending rate (SL). The third and fourth factors constituted measurement indicators that proxied banks' competition and bank regulations viz. Boone Indicator (BO), Panzar-Rosse H-Statistics (HS) and the Lerner Index (LI), capital adequacy (CA), asset quality (AQ) and debt to operating income ratio of banks (DI). The uniqueness column represents the error term of the variables that are not explained by the existing three factors. The Z-score (ZS) and standard deviation of bank's lending rate (SL) have the highest unique value at 0.19. This implies that $19 \%$ of the residual of ZS and SL are not explained by the second factor.

\subsection{Reliability and Adequacy Test}

Table 6 shows the outcome of Cronbach's Alpha (CA) reliability test. We utilized the CA test to check for the internal reliability of our data. We estimated CA by evaluating the score of a single scale variable with the total score of all observations and then compared the outcome with the variance of each single variable score. The coefficient of alpha $(\alpha)$ varies between 0 and 1 . When $(\alpha)=1$ the variables are dependent of each other and therefore are correlated or share the same covariance but when $(\alpha)=0$ the variables being tested are mutually exclusive. Scores that is higher than 0.70 meet the expected threshold. However, some studies (see e.g. Tavakol and Dennick, 2011) propose a score higher than 0.90 and above. All our variables of interest are statistically significant since the calculated correlation between the scale validity coefficient and the square root of alpha $(\sqrt{0.79})$ is slightly close to 0.90 . The variables of interest are therefore constant and reliable to explain the link between bank concentration, competition, bank regulation and financial stability. This is reflected by CA of 0.79 
and average interim correlation of 0.24 .

Table 6: Cronbach's Alpha Reliability Test

\begin{tabular}{|l|l|l|l|l|l|l|}
\hline Item & Obs & Sign & $\begin{array}{l}\text { Item-test } \\
\text { correlation }\end{array}$ & $\begin{array}{l}\text { Item-rest } \\
\text { correlation }\end{array}$ & $\begin{array}{l}\text { Average } \\
\text { correlation }\end{array}$ & Interim \\
\hline CR & 28 & - & 0.82 & 0.78 & 0.26 & 0.77 \\
\hline HH & 28 & - & 0.78 & 0.74 & 0.28 & 0.80 \\
\hline BO & 28 & + & 0.77 & 0.72 & 0.25 & 0.76 \\
\hline HS & 28 & - & 0.61 & 0.58 & 0.25 & 0.76 \\
\hline LI & 28 & - & 0.80 & 0.76 & 0.23 & 0.89 \\
\hline CA & 28 & + & 0.78 & 0.74 & 0.26 & 0.81 \\
\hline AQ & 28 & + & 0.85 & 0.83 & 0.27 & 0.76 \\
\hline DI & 28 & + & 0.74 & 0.69 & 0.24 & 0.74 \\
\hline ZS & 28 & + & 0.63 & 0.60 & 0.27 & 0.72 \\
\hline CB & 28 & + & 0.81 & 0.77 & 0.21 & 0.86 \\
\hline SB & 28 & + & 0.61 & 0.58 & 0.18 & 0.70 \\
\hline SL & 28 & + & 0.77 & 0.72 & 0.24 & 0.89 \\
\hline TEST SCALE & & & & & & 0.79 \\
\hline
\end{tabular}

We further used the Kaiser-Meyer-Olkin (KMO) test to calculate the sampling competence for each variable and the whole model. Individual KMO results for each variable and the whole model is presented in Table 7. Higher KMO values imply that our model is consistent for factor analysis. KMO values vary between 0 and 1 . Kline (2011) suggests that higher KMO values above 0.70 shows that the variables of interest are correlated and the use of factor analysis is justified. The outcome of our data shows a KMO of 0.86 which is higher than 0.7. This justifies the use of factor analysis.

Table 7: Kaiser-Meyer-Olkin (KMO) Measure of Sampling Adequacy

\begin{tabular}{|l|l|}
\hline Variable & KMO \\
\hline CR & 0.86 \\
\hline HH & 0.90 \\
\hline BO & 0.88 \\
\hline HS & 0.89 \\
\hline LI & 0.84 \\
\hline CA & 0.91 \\
\hline AQ & 0.87 \\
\hline DI & 0.82 \\
\hline ZS & 0.85 \\
\hline CB & 0.92 \\
\hline SB & 0.80 \\
\hline SL & 0.77 \\
\hline Overall & 0.86 \\
\hline
\end{tabular}

\subsection{Confirmatory Factor Analysis (CFA)}

We used CFA to evaluate the theorized link between the observable estimated variable and the latent construct. CFA is applicable when establishing both convergent and discriminant validity of theoretical constructs which are adjusted for estimated errors. To ensure that our data is valid, we estimated an unstandardized recursive model. The major function of CFA is to get estimates for each calculated variable in the model and identify all estimation residuals precisely before estimating SEM. We start by making sure that the model has been identified by accomplishing distinct set of estimation parameters with unknown values. We set a measurement scale of unobserved latent construct variables variance to 1.00 (Brown, 2006). In our case, we placed a factor loading of unit to 5 banks concentration ratio (CR), the Lerner Index (LI), capital adequacy (CA) and the Z-score (ZS).

Further, we check for the validity of parameters in CFA by checking the goodness of fit of our model. If we confirm that our model is fit, we then continue with our analysis to explain the coefficients path in the model. There are several methods used to measure goodness of fit. However, the best measure remains contestable (Hu and Bentler, 1999; Schrieber et al., 2008; Garson, 2010; Kline, 2011). We used the most commonly used goodness of fit methods which comprised of: Comparative Fit Index (CFI), Tucker Lewis Index (TLI), relative Chi-square (CMIN/DF), Standardized Root Mean Residual (SRMR) and Root Mean Square Error of Approximation (RMSEA). For the model to be a good fit: CFI and TLI should be greater or equal to 0.90 (Garson, 2010; Hu and Bentler, 1999); CMIN/DF should be four or less, but not less than one (Kline, 2011); RMSEA and SRMR should be less or equal to 0.05 (Schrieber et al., 2008).

We started performing a CFA on bank concentration as a latent construct and its measurement variables, which include concentration of five banks' assets (CR) and the Herfindahl-Hirschman Index (HH). These variables 
were allowed to freely correlate with each other but their error terms were mutually exclusive (Bryne, 2001). Figure 3 shows the path analysis of the CFA results of bank concentration as the latent construct.

To ensure that our model was well identified we placed a factor loading of one on 5 banks' concentration ratio (CR). This is because the concentration ratio of five largest banks is highly correlated to the banking sector as shown in our factor rotation matrix. Constraining an indicator variable allows us to determine the relationship between the latent construct and the exogenous indicator variable in a recursive model. Our identification results showed that the measurement parameter variables well identified our model.

Theory predicts that bank concentration rises with an increase in the concentration ratio of assets of the 5 largest banks (Kline, 2011). Our estimation weights of bank concentration as a latent variable in forecasting the measurement variables (concentration ratio of 5 largest banks (CR) and Herfindahl-Hirschman (HH)) was statistically meaningful at P-value smaller than 0.05 . The estimation weight of bank concentration in predicting the $\mathrm{HH}$ was estimated at 0.17 . This implies that when bank concentration increases by one unit then the banking sector experiences a medium level concentration at 0.17 . This outcome is consistent with Galetic and Obravodic (2018) who suggested that bank concentration is medium if it ranges between 0.1 and 0.18 .

Figure 3: CFA for Bank Concentration and its Observed Variables

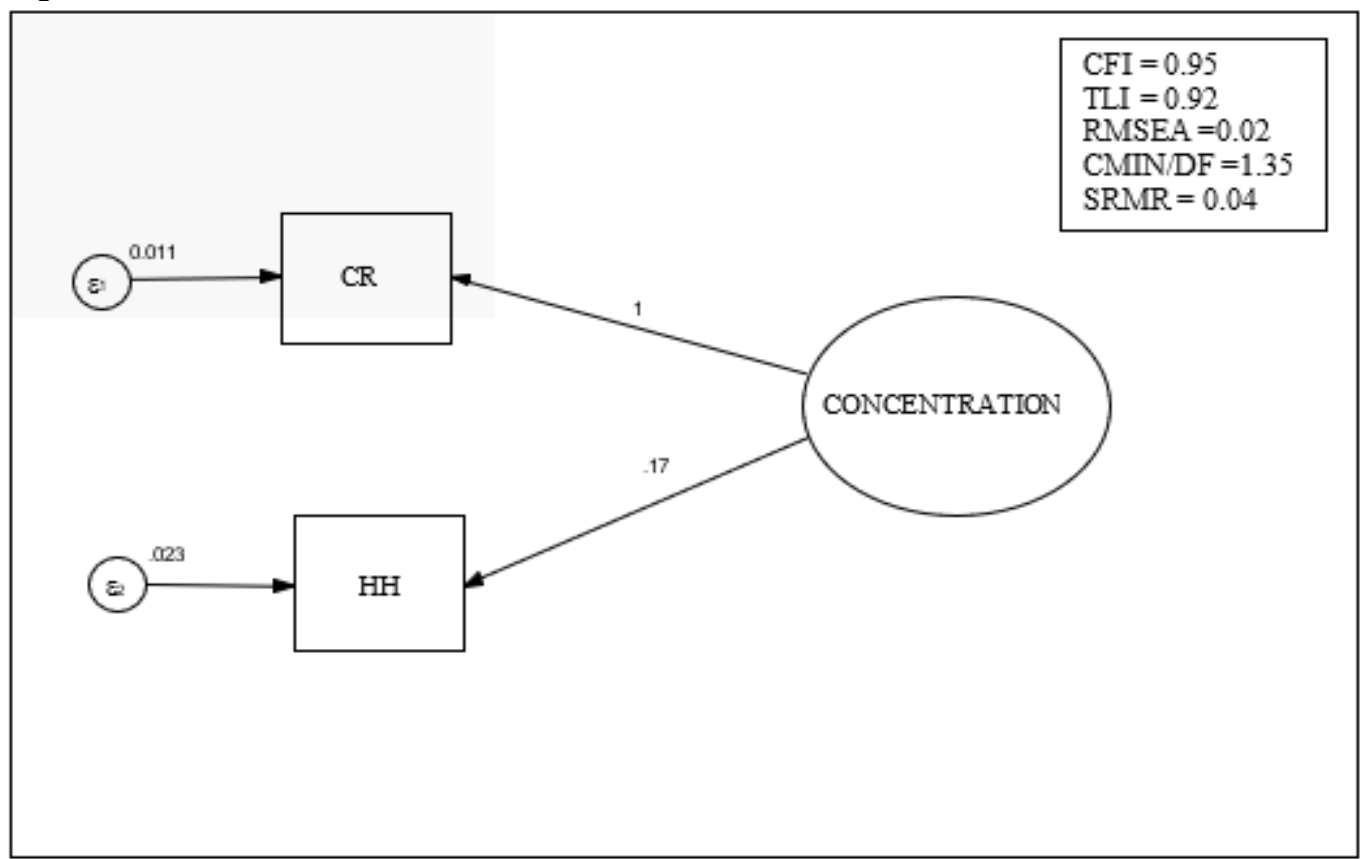

Note: CFI is Comparative fit index, TFI is Tucker Lewis Index, RMSEA is Root Mean Square Error of Approximation, CMIN/DF is Relative Chi-Square Value and SRMR is standardized root mean residual.

We further conducted a goodness of fit measure on the measurement variables. The outcome of our goodness of fit indices shows that our measurement variables have significant factor loadings to represent bank concentration. Our goodness of fit outcome is shown in Figure 4.

We also conducted a path analysis on the measurement variables of competition as our latent construct. Figure 4 presents the CFA results for competition and its observed variables. Competition is estimated using the Boone Indicator (BO), the H-statistics (HS) and the Lerner Index (LI). To ensure that our latent variable is well identified we set a factor loading of unit on LI. Our evaluation weights of competition as a latent construct in forecasting the measurement variables that include BO and HS were statistically significant at P-value less than 0.05. This suggested that when competition increases by one unit then the BO and HS would have increased in absolute terms by 0.65 and 0.85 respectively. This proves that the measurement variables of competition had a significant factor loading (Park, 2013). 
Figure 4: CFA for Competition and its Observed Variables

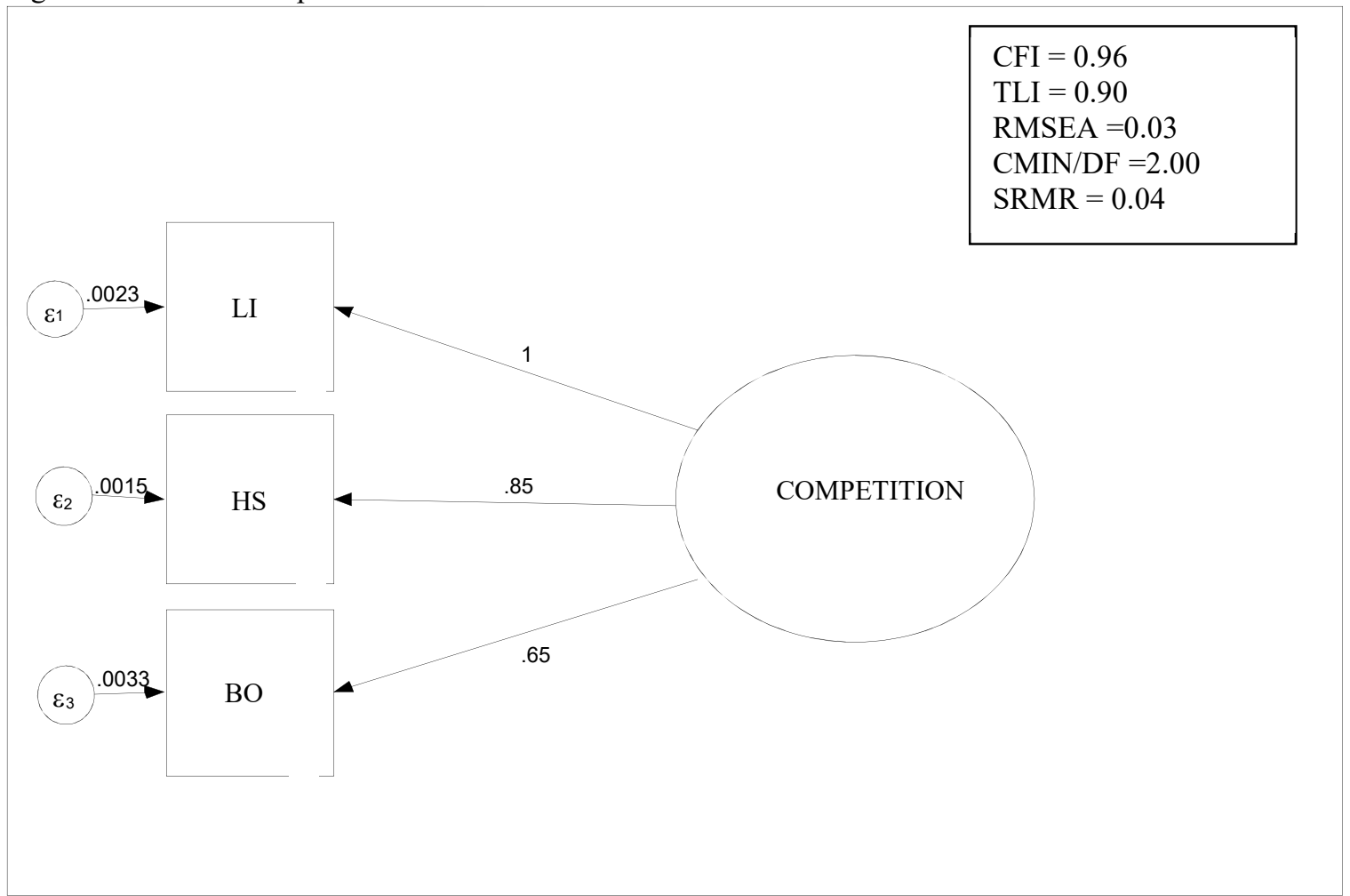

Note: CFI is Comparative fit index, TFI is Tucker Lewis Index, RMSEA is Root Mean Square Error of Approximation, CMIN/DF is Relative Chi-Square Value and SRMR is standardized root mean residual.

We further measured the goodness of fit of our model. The results extracted from the estimation shows that the measurement variables that represent the latent variable (competition) have a significant measure of goodness of fit as shown in Figure 4. Therefore, the factor loadings of the measurement variables are significant to proxy competition (latent construct).

We additionally performed a CFA on bank regulation as a latent exogenous variable. Measurement variables that represent our latent construct include capital adequacy (CA), asset quality (AQ) and debt to operating income ratio (DI). The regression weight of bank regulation in predicting capital adequacy was set at 1.00 based on existing theoretical conjecture that emphasize on high values of capital adequacy ratio to represent a stable banking system. Our regression weights of bank regulations as a latent construct in estimating the measurement variables that comprise of AQ and DI were statistically significant at P-value less than 0.05 . This implies that when bank regulation improves by one unit AQ and DI improves by 0.75 and 0.91 respectively. This confirms that the measurement indicators of bank regulations had a significant factor loading. This finding is consistent with that of Camara et al. (2013) and Bruno et al., (2014). Figure 5 shows CFA for bank regulation and its measurement variables. 
Figure 5: CFA for Bank Regulations and its Observed Measurement Variables

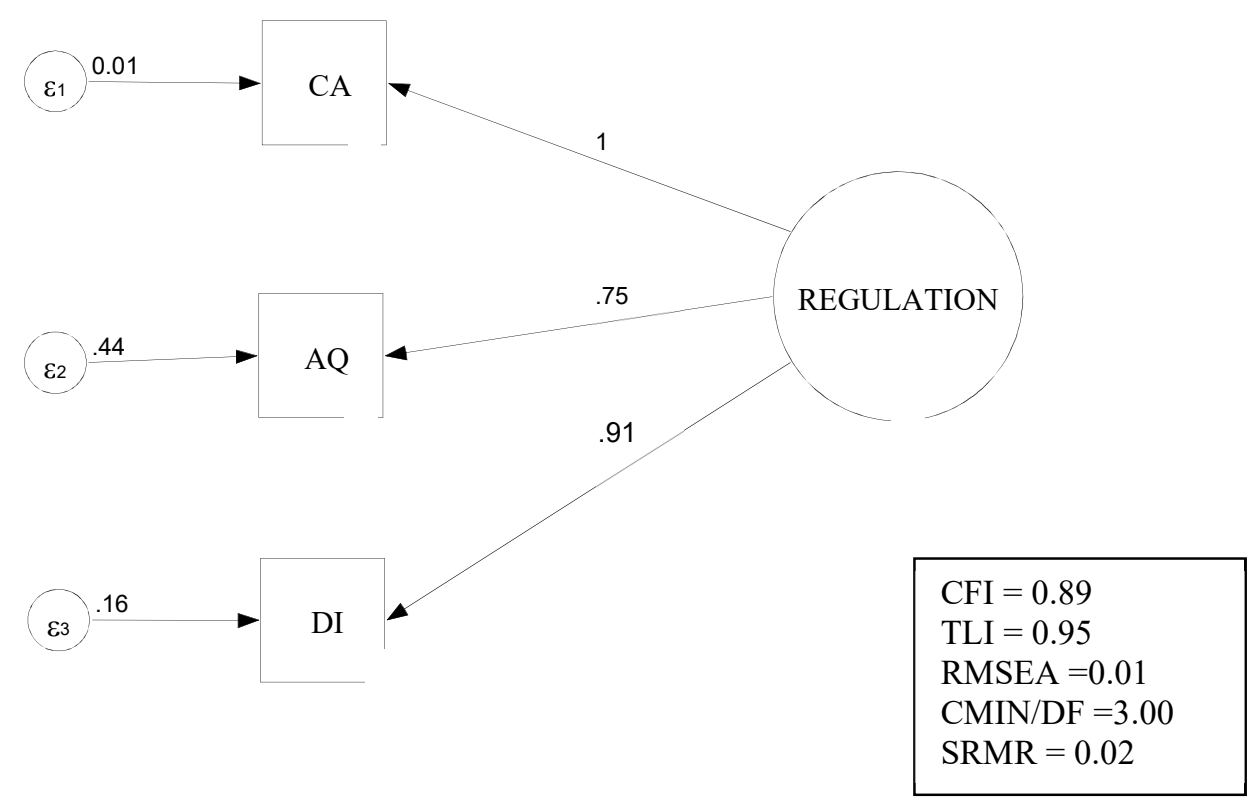

Note: CFI is Comparative fit index, TFI is Tucker Lewis Index, RMSEA is Root Mean Square Error of Approximation, CMIN/DF is Relative Chi-Square Value and SRMR is standardized root mean residual.

Five goodness of fit tests showed that our model fits well. This implied that our measurement variables were well fit to explain the latent construct (bank regulation). Our goodness of fit results is shown in Figure 6. Finally, we performed a CFA on financial stability as latent exogenous variables and its proxy for observed endogenous variables that include the Z-score (ZS), ratio of credit provision to bank deposit (CB), Standard deviation of banks' lending rate (SL) and standard deviation of banks' deposit rate (SB). The estimation weight for financial stability in forecasting the Z-score was fixed at 1.00 in line with theoretical underpinnings that assert higher value of Zscore depict greater banking stability (Li et al., 2017). The estimation weight for financial stability in projecting $\mathrm{CB}, \mathrm{SL}$ and SB were all statistically significant at P-value below 0.05 . Regression weight of financial stability in forecasting standard deviation of banks' lending rate (SL) and standard deviation of banks' deposit rate (SB) was estimated at 0.28 and 0.36 respectively.

This suggests that when financial stability increases by a unit SL and SB changed by 0.28 and 0.36 respectively. Nevertheless, the deviation is not widely spread from zero, which implies that the variation is not so large to impede growth. When the variation is small and positive banks will be able to forecast future returns from lending interest rates and at the same time attract deposits through stable deposit rates (Cihak et al., 2016). The regression weight of financial stability in predicting ratio of credit provision to bank deposits was estimated at 0.63 . This implies that when financial stability improves by one unit, CB reduces by 0.63 units ceteris paribus. There is evidence therefore that the measurement variables that proxy financial stability has significant factor loadings. Figure 6 shows the CFA for financial stability and its estimated variables. 
Figure 6: CFA for Financial Stability and its Observed Variables

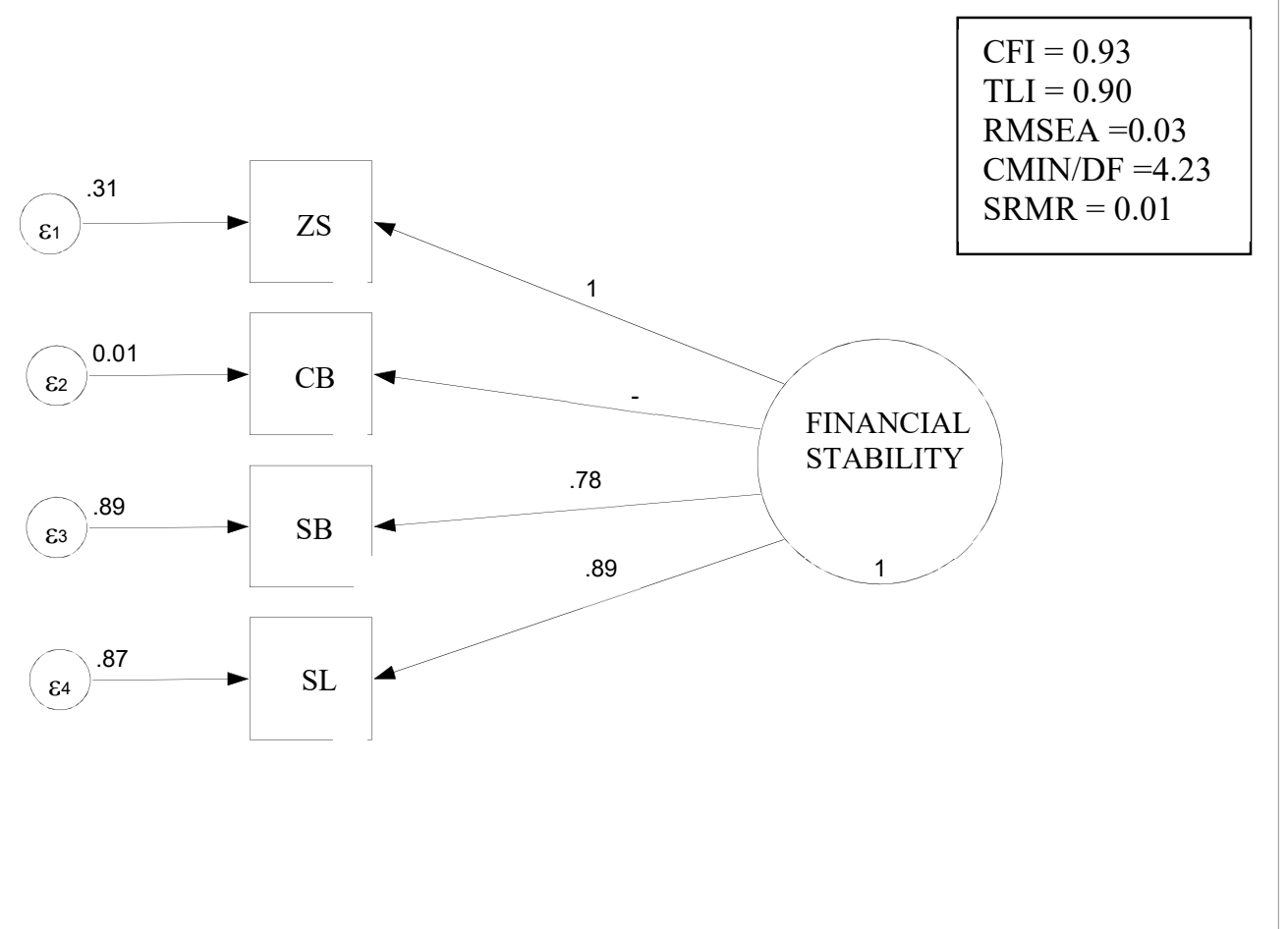

Note: CFI is Comparative fit index, TFI is Tucker Lewis Index, RMSEA is Root Mean Square Error of Approximation, CMIN/DF is Relative Chi-Square Value and SRMR is standardized root mean residual.

We also conducted a goodness of fit test to check if the measurement variables that proxy financial stability in the model met the pre-requisite threshold. All the goodness measures apart from the Chi-Square reported a best fit as shown in Figure 6. Hence, we conclude that the factor loadings for the endogenous measurement variables could be relied upon to proxy financial stability.

\subsection{Structural Equation Model Results}

The structural link between bank concentration, competition (mediating latent construct), bank regulation (control latent construct) and financial stability is depicted in Figure 7. The unstandardized coefficient trail of: 5-bank assets concentration ratio (CR), the Lerner Index (LI), capital adequacy (CA) and the Z-score (ZS) were constrained to unit in line with sound theoretical underpinnings (Kline, 2011). For that reason, there was no test of significance for these three paths.

The measureable endogenous variables included: the five banks concentration ratio, Herfindahl-Hirschman Index, Boone Indicator, H-statistics, Lerner Index, capital adequacy, asset quality, debt to income ratio, Z-score, ratio of credit provision to bank deposit, standard deviation of banks' lending rate and standard deviation of banks' deposit rate. The unobserved measureable endogenous variable comprised of competition and financial stability while the unobserved exogenous measureable variable included bank concentration, bank regulations and the residual terms $\varepsilon_{1}$ to $\varepsilon_{15}$.

The estimation weight for bank concentration in prediction of financial stability was inversely correlated and statistically significant at p-values less than 0.05 . This implies that when bank concentration increases by one unit it reduces financial stability by 0.68 units ceteris paribus. Therefore, this suggests that increase in bank concentration may induce banks to increase cost of service provision as well as interest rates. This attracts highrisk borrowers, which in turn increases probability of default. High credit risks lead to a reduction in asset quality leading to banks being exposed to systemic risks. Higher concentration will further induce banks to undertake risky ventures leading to a moral hazard problem. This is attributed to policies that are introduced to protect big banks from failing. Our estimation result therefore supports the 'concentration-fragility' hypothesis and is consistent with existing empirical studies that include Berger et al. (2009), Soedarmono et al. (2013) and Feldman (2015) 
Figure 7: SEM Estimation Results for Bank Concentration and Financial Stability

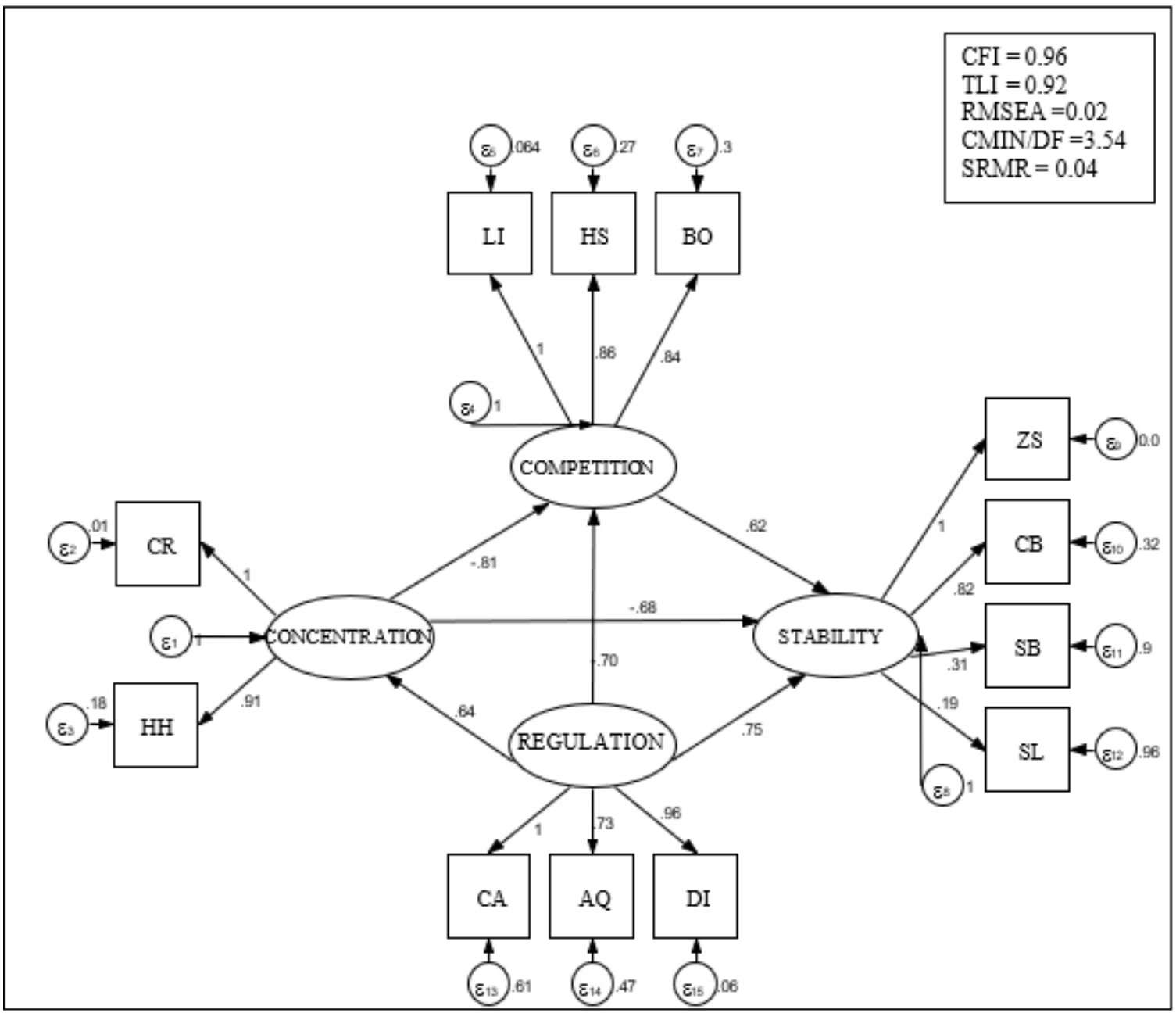

Variables that proxy bank competition (BO, HS, LI) portray a statistically significant positive correlation with variables that represent financial stability $(\mathrm{ZS}, \mathrm{CB}, \mathrm{SB}, \mathrm{SL})$ at P-value below 0.05 . Our result supports the competition-stability channel. This implies that a unit increase in competition would improve financial stability by 0.62 units, all other factors held constant. Less competition provides incentive for banks to take excessive risks, which renders the banks vulnerable to systemic risks. Similar findings have been documented by Amidu and Wolfe (2012) and Owen and Pereira (2016). The level of bank concentration in Kenya has therefore enhanced bank competition leading to a stable financial system over time (see Kamau et al., 2009; Gudmundsson et al., 2013; Mdoe et al., 2015).

Regression results using control variable suggest that bank regulation is significant and positively correlated to financial stability and bank correlation. In addition, bank regulations are inversely correlated with competition. A unit increase in regulation leads to improvement of financial stability by 0.75 other factors held constant. Consequently, a unit increase in bank regulation increases bank concentration by 0.64 units ceteris paribus. Introducing strict bank regulations that ensure adequate capital and improved asset quality guarantees financial stability. Further, it reduces debt to operating income ratio, which is a proxy for financial system stability (Alhassan et al, 2014).

Tight bank regulations also make incompetent banks to exit the market and facilitate mergers by banks to meet the required threshold. This leads to increased concentration in the market because few competent banks remain to provide services. Our finding is consistent with that of Tsenova (2016). We also find out that a unit improvement of bank regulation reduces competition by 0.70 units. Strict bank regulations increase bank concentration and reduce competition in the banking sector. When banks are few in the market they may form cartels to control the cost of providing banking services. This reduces competition and forms a monopoly market (Jimez et al., 2013).

The regression results also suggested that the variances of the measurement variables for the four latent constructs (bank concentration, competition, regulation and financial stability) were all statistically significant at P-value less than 0.05. This suggests that the variables were well spread which is a sign of an ideal model. To 
check whether the fit indices are accepted or rejected a goodness of fit test was conducted. The goodness of fit results of bank concentration, competition, regulation and financial stability are reported in Figure 7 . The results showed that the model met the acceptable threshold hence confirming that there is a significant relationship between the three latent constructs in our model.

\section{Conclusion}

This study sought to explore the link between bank concentration and financial stability with competition as an intervening variable. We used data from GFDD and CBK for the period 2004-2016 to estimate the weights of each measurement variable; we further conducted an exploratory and confirmatory factor analysis. To validate the association between the exogenous latent construct (bank concentration) and the two endogenous latent variables (competition and financial stability) a recursive standardized SEM analysis was performed.

The study identifies a series of new findings and policy implications. SEM analysis confirms that the Kenyan banking sector follows the 'concentration-fragility' hypothesis. Further, competition plays a significant role in ensuring stability of the financial system hence supporting the 'competition-stability' hypothesis. These findings suggest that for the financial system to be stable there should be less concentration and high competition in the Kenyan banking sector. Therefore, through constructive de-regulation and liberalization of the banking sector, policy makers should introduce policies that encourage easy entry and exit of banks in the market to reduce concentration in the Kenyan banking sector. Such policies should include easy registration of both foreign owned and domestic owned banks and also ensuring that the government owns fewer shares in existing banks to reduce its monopoly power.

Furthermore, to encourage competition in the banking sector and in line with Vision 2030 economic blueprint the government should encourage merging of small banks to ensure there is efficiency and introduce an effective institutional framework that would facilitate easy supervision and regulation of the entire banking industry. Policy makers should also introduce policies that encourage inventions and innovations in the banking sector to encourage effective delivery of services at lower cost and to ensure that efficient banks are well compensated for their services Information sharing should also be encouraged through full disclosure of books of accounts so as to show the financial standing and market share of a given bank relative to other banks. Based on our findings and policy implications we conclude that indeed bank concentration and competition have an effect on financial stability in Kenya. Specifically, Kenyan banking system tends to support 'concentration-fragility' and 'competition-stability' hypotheses. Further, regulation negatively affects competition while it has a positive effect on regulation and bank concentration.

\section{References}

Aghion, P., Bloom, N., Blundell, R., Griffith, R., \& Howitt, P. (2005): Competition and Innovation: An InvertedU Relationship. The Quarterly Journal of Economics, 120(2), 701-728.

Agoraki, M., Delis, M., \& Pasiouras, F. (2011). Regulations, Competition and Bank Risk-Taking in Transition Countries. Journal of Financial Stability, 7(2), 38-48.

Alhassan, A. L., Kyereboah-Coleman, A., \& Ando, C. (2014). Asset Quality in a Crisis period: An Empirical Examination of Ghanaian Banks. Journal of Review of Development Finance, 4 (1), 50-62.

Ali, M. S., Timoumi, I., \& Rami, Z. (2015). Banking Concentration and Financial Stability: Evidence from Developed and Developing Countries. Economics Discussion Papers, No 2015-22, Kiel Institute for the World Economy.

Amidu, M., \& Wolfe, S. (2013). The Effect of Banking Market Structure on the Lending Channel: Evidence from Emerging Markets. Review of Financial Economics, 22, 146-157.

Bain, J. S. (1959). Industrial Organization. John Wiley and Sons, New York.

Bara, A., Mugano, G., \&Le Roux, P. (2017). Bank Concentration, Country Income and Financial Development in SADC. Journal of Southern African Business review, 2(1), 23-45.

Beck, T., Demirgüç-Kunt, A., \& Levine, R. (2003). Bank Concentration and Crises. The World Bank, Washington, DC, Policy Research Working Paper Series No. 3041.

Berger, A. N., Demirgüç-Kunt, A., Levine, R. \& Haubrich, G. J. (2004). Bank Concentration and Competition: An Evolution in the Making. Journal of Money, Credit and Banking, 36, 433-451.

Beck, T, Demirguc-Kunt, A. \& Merrouche, Q. (2013). Islamic Versus Conventional Banking Business Model, efficiency and Stability. Journal of Banking and Finance, 37, 433-447.

Berger, A. N., Demirgüç-Kunt, A., Levine, R. \& Haubrich, G. J. (2004). Bank Concentration and Competition: An Evolution in the Making. Journal of Money, Credit and Banking, 36, 433-451.

Berger, A. N., Klapper, L. F. \&Turk-Ariss, R. (2008). Bank Competition and Financial Stability. The World Bank, Policy Research Working Paper. No. 4696.

Berger, A. N., Klapper, L. F., \& Turk-Ariss, R. (2009). Bank competition and Financial Stability. Journal of Financial Services Research, 35(2), 99-118. 
Berger, A., \& Bowman, C. (2013). How does capital affect bank performance during financial crises? Journal of Financial Economics, 109, 146-176.

Bikker, J. A., \& Haaf, K. (2002). Competition, Concentration and their Relationship: An Empirical Analysis of the Banking Industry. Journal of Banking\& Finance, 26(11), 2191 - 2214.

Blunch, N.J. (2008). Introduction to Structural Equation Modeling Using SPSS and AMOS. London: Sage Publications.

Boone, J. (2008). A New Way to Measure Competition. Economic Journal, 118(531), 1245-1261.

Borio, C. (2003). Towards a Macro prudential Framework for Financial Supervision and Regulation? Bank for International Settlement, Working Paper No. 128.

Boyd, J. H., \& De Nicolo, G. (2005). The Theory of Bank Risk Taking and Competition Revisited. The Journal of Finance, 60(3), 1329-1343.

Brown, T. A. (2006). Confirmatory Factor Analysis for Applied research. Guilford Publications.

Bruno, V., Shim, I., \& Shin, H. S. (2014). Comparative Assessment of Macro Prudential Policies. Bank for International Settlement, Working paper 502.

Camara, B., Distinguin, I.,\& Roulet, C. (2013). Bank regulatory capital and Liquidity: Evidence from US and European Publicly Traded banks. Journal of Banking and Finance, 37(2), 3295-3317.

Catena, M. (200). Efficiency Structure Hypothesis: An Application to the Argentine Banking Sector. Central Bank of Argentine Republic, Working Paper No. 12.

Central Bank of Kenya, (2007-2017). Kenya Financial Sector Stability Report. Various Issues 2007-2016. Central Bank Printer.

Central Bank of Kenya, (1990-2017). Kenya Banking Supervision Annual Report. Various Issues 1996- 2017. Central Bank Printer. Available at http://www.centralbank.go.ke.

Cerruti, E., Jihad, D., \& Dell'Aricca G. (2015). Housing Finance and Real-Estate Boom: a Cross-Country perspective. IMF Staff Discussion Note, SDN/15/12.

Claessens, S., \& Laeven, L. (2004). What Drives Bank Competition? Some International Evidence. Journal of Money, Credit and Banking, 36(3), 563-583.

Ciapanna, E., \& Rondinelli, C. (2011). Retail Sector Concentration and Price Dynamics in the Euro Area: A Regional Analysis. SSRN Electronic Journal, retrieved at 10.2139/ssrn.2023086.

Cifter, A. (2015). Bank Concentration and Non-Performing Loans in Central and Eastern European Countries. Journal of Business Economics and Management. 16(1), 54-78.

Cihak M.,\& Melecky M. (2016). The Nexus of Financial Inclusion and Financial Stability: A Study of Possible Trade-offs and Synergies. The Word Bank, Policy Research Paper Series.

Cuestas, J. C., Lucotte Y., \& Reigl, N. (2017). Banking Sector Concentration, Competition and Financial Stability: The Case of the Baltic Countries. Eesti Pank Working Paper 7.

Davies, S.W. (1979), Choosing between Concentration Indices: The Iso-Concentration Curve, Economica, 46(1), $67-75$.

Demirguc-Kunt, A., \& Detragiache, E. (2002). Does Deposit Insurance Increase Banking System Stability? An Empirical Investigation. Journal of Monetary Economics, 49(7), 1373-1406.

Demirgüç-Kunt, A. \& Huizinga, H. (2010). Are Banks Too Big to Fail or Too Big to Save? International Evidence from Equity Prices and CDS Spreads. The World Bank, Washington, DC, Policy Research Working Paper 5360 .

Demsetz, H. (1974). Two Systems of Belief about Monopoly. In H. Goldschmidt, H. Michael Mann and J. Fred Weston, eds. Industrial Concentration: The New Learning. Boston: Little, Brown and Co. 164-84.

Evrensel, A. Y. (2008). Banking Crisis and Financial Structure: A survival-time analysis. International Review of Economics \& Finance, 17(4), 589-602.

Feldman, H. (2015). Banking System Concentration and Unemployment in Developing Countries. Journal of Economics and Business, 77, 60-78.

Fernandez, A. I., Gonzalez, F., \& Suarez, N. (2010). How Institutions and Regulation Shape the Influence of Bank Concentration on Economic Growth: International Evidence. International Review of Law and Economics, 30(1), 28-36.

Freixas, X., \& Rochet, H. (2008). Microeconomics of Banking.2nd ed., MIT Press.

Frey, R. \& Hledik, J. (2018). Diversification and Systematic Risks: A financial Network Perspective. Risks, 6(2), 54.

Galetic, F., \& Obravodic, T. (2018). Measuring Concentration of the Banking Market of the Republic of Croatia, In: Tipuric, Darko Labas, Davor (Ed.): 6th International OFEL Conference on Governance, Management and Entrepreneurship.

Garson, D.G., (2010). Reliability Analysis. Statnotes: Topics in Multivariate Analysis, North Carolina State University.

Gudmundsson, R., Ngoka-Kisinguh, K., \& Odongo, M. T. (2013). The Role of Capital Requirements on Bank 
Competition and Stability: The Case of the Kenyan Banking Industry. Nairobi: Kenya Bankers Association.

Henson, R. K. \& Roberts, J. K. (2006). Use of Exploratory factor Analysis in Published Research: Common Errors and some Comments on Improved Practice. Journal of Educational and Psychological Measurement, 66(1), $393-416$

Hu, L.T., \& Bentler, P.M. (1999), Cut-off Criteria for Fit Indexes in Covariance Structure Analysis: Conventional Criteria versus New Alternatives. Structural Equation Model, 6(1), 1-55.

Hu, T., \& Xie, C. (2016). Competition, Innovation, Risk-Taking, and Profitability in the Chinese Banking Sector: An Empirical Analysis Based on Structural Equation Model. Discrete Dynamics in Nature and Society, 32(1), $25-56$.

Jimenez, G., Lopez, J. A., \& Saurina, J. (2013). How Does Competition Affect Bank Risk-Taking? Journal of Financial Stability, 9(2), 185-195.

Kamau, A., Karingi, S., Ndung'u, N., \& Mwaura, S. (2004). Capital Requirements and Bank Behavior in Kenya: Empirical Evidence. KIPPRA Discussion Paper No. 36.

Kline, R.B. (2011). Principles and Practice of Structural Equation Model, Second Edition: Guilford Publications.

Kick, T., \& Prieto, E. (2015). Bank Risk and Competition: Evidence from Regional Banking Markets. Journal Review of Finance, 19(3), 1185-1222.

Kumankoma, S. E., Abor, Y. J., Aboaagye, A., \& Amidu, W. (2018). Freedom, Competition and Bank Profitability in Sub-Saharan Africa. Journal of Financial Regulation and Compliance, 10, 1108-1134.

Lerner, A. P. (1934). The Concept of Monopoly and the Measurement of Monopoly Power. Review of Economic Studies, 1(3), 157-175.

Leroy, A., \& Lucotte, Y. (2016). Is there a competition-stability trade-off in European banking? Journal of International Financial Markets, Institutions and Money,3, 123-156.

Li, C. H. (2016). The Performance of ML, DWLS and ULS Estimation with Robust Correction in Structural Equation Models with Ordinal Variables. Journal of Psychological Methods, 21(3), 369-387.

Li, X., Tripe, D., \& Malone, C. (2017). Measuring Bank Risk: An Exploration of Z-score. Massey University, Palmerstone North, new Zealand.

Mdoe, I. J., Omolo, J.O., \& Wawire, N. H. (2016). The Dynamics of Bank Competition in Kenya. Retrieved fromhttps://editorialexpress.com/cgi-bin/conference/download.cgi? db.

Mishkin, F. (1999). Financial consolidation: Dangers and opportunities. Journal of Banking \& Finance, 23(2-4), 675-691

Owen, A. L.,\& Pereira, J. (2018). Bank Concentration, Competition, and Financial Inclusion. Retrieved at SSRN: https://ssrn.com/abstract $=2836521$.

Panzar, J. C., \& James, N. R. (1987). Testing for Monopoly Equilibrium. Journal of Industrial Economics, 35(1), 443-456.

Park, H. K. (2013). Testing for Competition in the South Korean and Chinese Commercial Banking Markets. Journal of Financial Studies, 42(1), 56-75.

Sahile, W. G., Tarus, D., \& Cheruiyot, T. (2015). Market structure-performance hypothesis in Kenyan banking industry. International Journal of Emerging Markets, 10(2), 697-710.

Sanya, S., \& Wolfe, S. (2011). Can Banks in Emerging Economies Benefit from Revenue Diversification? Journal of Financial Services Research, 40, 79-101.

Schreiber, J. B. (2008). Core Reporting Practices in Structural Equation Modelling. Journal of Research in Social and Administrative Pharmacy, 4(2), 83-97.

Shijaku, G. (2017). Does Concentration Matter for Bank Stability? Evidence from the Albanian Banking Sector. Journal of Central Banking Theory and Practice, 3(4), 67-94.

Soedarmono, W., Machrouh, F., \& Tarazi, A. (2011). Bank Market Power, Economic Growth and Financial Stability: Evidence from Asian banks. Journal of Asian Economics, 22(6), 460 - 470.

Tabak, B., Fazio, D., \& Cajueiro, D. (2012). The Relationship between Banking Market Competition and RiskTaking: Do Size and Capitalization Matter? Journal of Banking and Finance, 36(12), 3366-3381.

Thompson, B. (2004). Exploratory and Confirmatory Factor Analysis: Understanding Concepts and Applications. Washington, D.C: American Psychological Association. International Standard Book Number: 1-59147-0935.

Titko, J., Skvarciany, V., \& Jurevicienè, D. (2015). Drivers of Bank Profitability: Case of Latvia and Lithuania. Intellectual Economics, 9(2), 120-129.

Tsenova, T. (2016). The Importance of Being Prudent: Capital Adequacy, Financial Stability and the Macro economy. Economic World Research Library, Tsenova Academic press.

Vives, X. (2010). Competition and stability in banking. CEPR, Policy Insight, No 50. 